\title{
Franco Garelli, Religion Italian Style. Continuities and Changes in a Catholic Country
}

Farnham, Ashgate, 2014, 244 p.

Jean-Louis Ormières

\section{OpenEdition}

\section{Journals}

Édition électronique

URL : http://journals.openedition.org/assr/27372

DOI : $10.4000 /$ assr. 27372

ISSN : $1777-5825$

Éditeur

Éditions de l'EHESS

Édition imprimée

Date de publication : 1 octobre 2015

Pagination : 307

ISBN : 978-2-7132-2515-4

ISSN : 0335-5985

Référence électronique

Jean-Louis Ormières, «Franco Garelli, Religion Italian Style. Continuities and Changes in a Catholic Country ", Archives de sciences sociales des religions [En ligne], 172 I octobre-décembre, mis en ligne le 24 mai 2016, consulté le 24 septembre 2020. URL : http://journals.openedition.org/assr/27372 ; DOI https://doi.org/10.4000/assr.27372

Ce document a été généré automatiquement le 24 septembre 2020

(c) Archives de sciences sociales des religions 


\section{Franco Garelli, Religion Italian Style. Continuities and Changes in a Catholic Country}

Farnham, Ashgate, 2014, 244 p.

Jean-Louis Ormières

\section{RÉFÉRENCE}

Franco Garelli, Religion Italian Style. Continuities and Changes in a Catholic Country, Farnham, Ashgate, 2014, 244 p. 
1 Co-auteur d'une grande enquête consacrée à La Religiosità in Italia publiée en 1995 (V. Cesareo, R. Cipriani, F. Garelli, C. Lanzetti, G. Rovati, La Religiosita in Italia, Arnoldo Mondadori Editore, Milano, 369 p.), Franco Garelli, s'appuyant sur une enquête approfondie réalisée à partir d'un échantillon représentatif de plus de 3000 personnes âgées de 16 à 74 ans, nous montre ici combien, malgré tous les changements intervenus depuis 20 ans, la religion conserve en Italie un caractère d'exception dans le paysage européen. Comment expliquer que malgré les signes indéniables d'une sécularisation (crise des vocations, baisse de la pratique, perte d'influence de l'Église, etc.), l'Italie demeure en Europe l'un des pays où le sentiment religieux est le plus répandu?

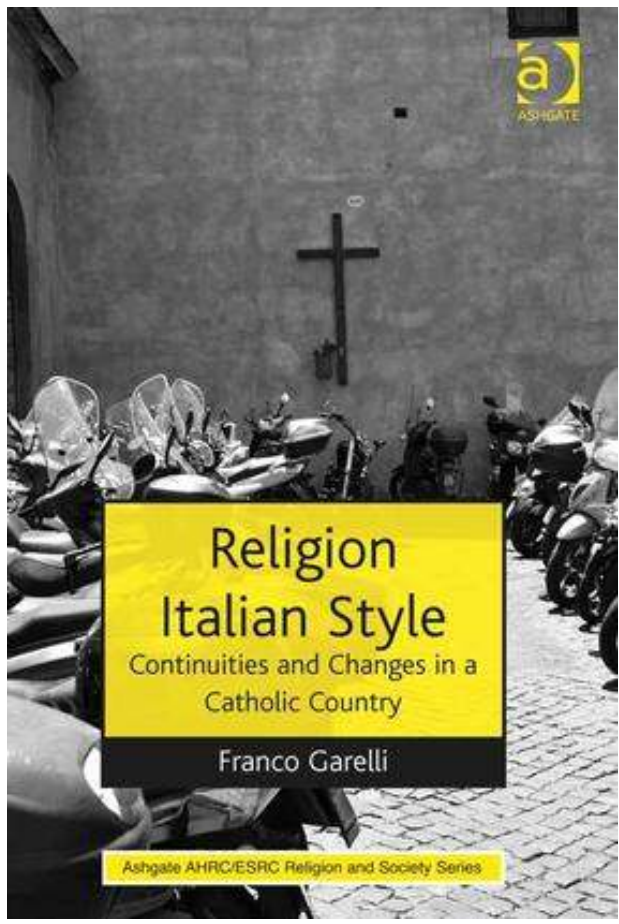
Comment expliquer que tant d'Italiens continuent de maintenir des liens avec le catholicisme ? Comment expliquer que des associations catholiques continuent de jouer un rôle important dans ce pays alors que d'autres formes associatives ont du mal à subsister? Comment expliquer que des athées «dévots» ou des hommes politiques "sécularisés " conservent une telle bienveillance envers le catholicisme ? Ce sont là autant de questions auxquelles l'auteur tente de répondre.

2 Attentif à l'hétérogénéité des catholiques italiens, F. Garelli distingue selon un continuum plusieurs catégories : les convaincus et actifs ; les convaincus mais peu ou moins actifs ; les catholiques par tradition et les catholiques « in my own way " (que l'on pourrait traduire par " à ma manière », assimilable à un catholicisme « bricolé »).

3 Le premier chapitre analyse le sentiment religieux dans un pays où, phénomène remarquable, la proportion de non-croyants ou de sans religion demeure inchangée depuis plusieurs années. Selon l'enquête, près de $46 \%$ des personnes interrogées déclarent être totalement convaincus de l'existence de Dieu. Ils sont plus de $80 \%$ à croire en la divinité et en la résurrection du Christ. En Italie, le phénomène du « believing without belonging " observé ailleurs en Europe est quasiment absent. Une forte majorité d'Italiens estiment que les progrès scientifiques n'ont guère d'incidence sur leur foi. Seul un tiers d'entre eux considèrent que les progrès scientifiques mettent à mal ou rendent plus malaisée leur croyance en Dieu. Le différentiel entre hommes et femmes demeure; quant au différentiel générationnel, il est encore plus prononcé. Enfin, l'enquête confirme l'hétérogénéité géographique de la péninsule; d'une part le Sud et les îles où près de $60 \%$ déclarent croire en Dieu avec certitude, d'autre part le centre et le Nord où prédomine l'incertitude et qui se caractérise par une forte concentration de «non-croyants».

4 L'expérience et la vie religieuses, objet du second chapitre, témoignent de la vitalité du catholicisme italien : plus de $72 \%$ des catholiques croient que Dieu veille sur eux et les protègent bien que la moitié ne croient plus dorénavant en l'existence du diable. 
Concernant la pratique (assistance à la messe), le différentiel demeure entre homme (18\%) et femme ( $35 \%)$, jeunes ( $17 \%)$ et personnes âgées ( $45 \%)$, Sud (31\%) et centre $(20 \%)$ du pays. Pour l'ensemble, il est néanmoins incontestable, comme le remarque l'auteur, que l'assistance à la messe du dimanche est devenue un phénomène minoritaire. Les cérémonies associées aux rites de passage (baptême, mariage, funérailles) continuent d'être majoritairement célébrées même si là aussi on observe des différences d'opinion sur leur importance selon les sexes, les générations et les régions. Bien qu'elle n'ait cessé de décliner au cours des dernières années, la dévotion populaire demeure encore active dans toute l'Italie.

5 La socialisation religieuse des personnes âgées, analysée dans le troisième chapitre, semble indiquer une relative et surprenante stabilité tout au long de leur vie. Il apparaît même que la participation des jeunes générations à l'instruction religieuse et aux activités sociales organisées par l'Église ne sont guère en déclin.

6 Les relations des Italiens avec l'Église (cinquième chapitre) demeurent encore très fortes. Plus des deux tiers des personnes interrogées déclarent avoir confiance dans l'institution. Mais pourtant, ils sont tout aussi nombreux à lui reprocher son inconsistance et sa trop grande influence dans la société. L'individualisme religieux ne cesse de progresser parmi les Italiens. Bien qu'une majorité admette que l'institution est essentielle dans la relation de l'homme avec Dieu, une forte minorité $(45 \%)$ croit pouvoir se passer du prêtre et de l'Église concernant leurs besoins religieux. Si les Italiens ont en majorité une image quelque peu négative du haut clergé, en revanche, ils conservent un réel attachement à leur paroisse. Une forte minorité se dit favorable au mariage des prêtres ( $47 \%$ ) et à l'ordination des femmes.

7 Dans le chapitre 6, Garelli, s'interrogeant sur les rapports qu'entretiennent les Italiens avec des spiritualités alternatives, constate qu'il s'agit plus souvent d'intentions que de pratiques. L'attrait pour le «nomadisme spirituel » demeure au niveau des idéaux plus que des faits à la différence de ce que l'on observe dans plusieurs pays européens. F. Garelli invite néanmoins ses collègues à travailler sur cette catégorie "spiritualité ». Pourquoi ne pas leur suggérer d'étudier également la catégorie « athéisme»?

8 Les Italiens restent comme par le passé bienveillants sur le rôle de la religion dans la sphère publique (chapitre 6). L'enquête montre en effet que plus des trois quarts sont favorables à la présence des crucifix dans l'espace public. Il en va tout autrement quand il s'agit de l'intervention sur les questions éthiques qui touchent à la vie privée (avortement, procréation artificielle, homosexualité). Sur ces points les Italiens sont très partagés en quatre tendances de dimension égale : les uns pensent que l'Église devrait pouvoir faire des propositions et trouver des solutions, d'autres pensent qu'elle devrait se borner à donner son opinion; d'autres encore qu'elle devrait se contenter de fixer les grands principes; enfin, un dernier groupe considère qu'elle doit rester en dehors du débat et s'en tenir aux seules questions spirituelles.

9 Le chapitre 7 examine l'attitude des Italiens envers le politique. Si l'époque où l'Église donnait des consignes de vote est bien révolue, les catholiques convaincus et peu engagés en politique ne cachent néanmoins pas leur préférence pour les partis du centre.

10 Comme la plupart des pays européens, l'Italie est confrontée au pluralisme religieux (Islam, Bouddhisme, religions orientales, New Age, etc). Ces minorités religieuses plus fortes dans le nord du pays se distinguent de la majorité catholique par une prépondérance des femmes et des jeunes et une plus forte dévotion. Ce pluralisme et en 
particulier la présence de l'islam, deuxième religion du pays n'est pas sans susciter, pour le moins, une ambivalence certaine : une forte majorité estime en effet qu'il s'agit là d'une source de conflit, près de la moitié y voit une menace pour l'identité italienne, mais plus de la moitié la perçoive comme une source d'enrichissement.

11 Tout en regrettant l'absence d'une conclusion, qui aurait permis de s'interroger sur les trajectoires futures du catholicisme italien, les résultats et l'analyse de cette importante enquête et les très nombreux graphiques et tableaux qui l'accompagnent en font un outil indispensable pour les chercheurs et plaident indubitablement en faveur de la lecture de cet ouvrage. 